\title{
Profecia autorrealizável e o novo normal pós-coronavirus
}

\section{Self-fulfilling prophecy and the new normal postcoronavirus}

Uajará Pessoa Araújo 1

Crystyane Ferreira Bernardino²

\section{Resumo}

Alicerçada em evidências oferecidas pela literatura, acolhe-se como ponto de partida teórico a proposição que as especulações podem tornar-se autorrealizáveis. Portanto, haveria mérito em estudar as especulações mais atuais, de ordem social e econômica, associadas com o coronavírus que assola o país - objetivo declarado deste trabalho; na medida em que parte do futuro pode estar sendo construído pelo consumo dessas previsões. Subordinando o trabalho à concepção subjetiva da realidade, ele foi conformado como qualitativo, descritivo, transversal, documental, à partir de matérias sobre o "Novo Normal" publicadas no jornal Folha de São Paulo, como fonte de dados que, tratados, passaram pela análise de conteúdo. Concluiu-se que há um conjunto significativo de matérias especulativas que apenas usam o Novo Normal como âncora para oferecer proposições que estariam em pauta mesmo sem a pandemia, por exemplo, a agenda socioambiental ou o uso intensificado de bicicletas. Como regra, as especulações são imprecisas, sem a preocupação de oferecer marcos temporais. São tecnicamente questionáveis ao não considerar cenários relevantes e prováveis, como a descoberta da vacina e de tratamentos eficazes ou de recrudescimento da pandemia pelo surgimento de cepa mais contagiosa e letal. Mas, independentemente de tais objeções, tais especulações não podem ser descartadas, pois estão sendo ventiladas e podem se tornar fato, não por estarem certas a priori, e sim, porque pessoas podem balizar seu comportamento nelas.

Palavras-chaves: Coronavírus; Covid-19; Profecia autorrealizável.

\begin{abstract}
Based on evidence gathered in the literature, this investigation took as a theoretical starting point the proposition that speculations can become self-fulfilling. Therefore, there would be merit in studying the most current speculations, of a social and economic order, associated with the coronavirus that plagues the country - the stated objective of this work: part of the future may be being built by the consumption of these forecasts. Subordinating the work to the subjective conception of reality, this was conformed as qualitative, descriptive, cross-sectional, documentary, which used materials about the Novo Normal published in the Folha de São Paulo newspaper as a source of data that were treated and passed through content analysis. It was concluded that there is a significant set of speculative matters that only use Novo Normal as an anchor to offer propositions that would be on
\end{abstract}

\footnotetext{
${ }^{1}$ Professor do Programa de Pós-Graduação em Administração do Centro Federal de Educação Tecnológica de Minas Gerais. Doutor em administração e em engenharia de produção. E-mail: uajara@efetmg.br.

2 Mestranda do Programa de Pós-Graduação em Administração do Centro Federal de Educação Tecnológica de Minas Gerais. Bacharel em Administração. E-mail: crys.ferber@gmail.com.
} 
the agenda even without the pandemic, for example, the socio-environmental agenda or the intensified use of bicycles. As a rule, speculations are inaccurate, without the concern of offering timelines. They are technically questionable when they do not consider relevant and probable scenarios, such as the discovery of the vaccine and effective treatments or the pandemic's upsurge due to the emergence of a more contagious and lethal disease. But, regardless of such objections, such speculations cannot be dismissed, as they are being aired and may become a fact, not because they are a priori right, but because people can mark their behavior on them.

Key-words: Corona virus; Covid-19, Self-fulfilling prophecy

\section{Introdução}

O continuum, de quando em quando, é abalado por um evento que resulta em transformações irreversíveis. Em termodinâmica, isso se dá quando não é possível o retorno ao estado inicial mesmo cessada a causa da mudança. Tal seria como em uma ocorrência natural cataclísmica, exemplificada na extinção do Cretáceo-Paleógeno, K-Pg, hipoteticamente, decorrente da colisão de um asteroide com a Terra; ou, em escala bem menor, sem tal contundência, a partir da ação humana e mais próximo da sociedade atual: as revoluções agrícola, industrial, francesa e americana; as invenções da penicilina e da internet, entre outras.

A partir das informações correntes e sem o imperdoável descaso com as perdas de tantas pessoas, não parece razoável admitir a COVID-19 com tal potência, se houver equivalência com outras pandemias que ceifaram vidas no passado, pois não seria fácil encontrar elementos atuais significativos em subordinação casual mais direta à peste negra, à cólera, à gripe espanhola e, mesmo, à AIDS.

No entanto, está em voga o termo "Novo Normal" (NN), representando um conjunto de especulações sobre como a vida será, (se) finda a pandemia, ou pelo menos a sua fase mais aguda. As previsões perpassam negócios, saúde, relações pessoais; são distribuídas e consumidas em jornais, redes sociais e mesmo, artigos científicos. Uma consulta rápida no Google Acadêmico retornou 2630 itens para a expressão de busca: "New Normal" and Coronavirus.

$\mathrm{Na}$ medida que a realidade é socialmente percebida e constituída (BERGER; LUCKMANN, 1966), tais especulações têm potencial efeito significativo no NN, modificando-o quando intenta revelá-lo ou, deliberadamente, ajustá-lo à conveniência dos interessados, frequente e convenientemente, ocultos. Enquanto a incredibilidade das previsões de Cassandra permitiu a destruição de Troia, a aceitação popular de presciências (expectativas) pode constituir-se em profecia autorrealizável (self-fulfilling prophecy, SFP).

Admitida a proposição de trabalho que o NN pode ser constituído, ainda que parcialmente, pela produção e consumo de SFPs, então é justificável inquiri-lo sob essa ótica, como nesta pesquisa, cujo objetivo é revelar como o NN é antevisto na imprensa brasileira, justificadamente preocupada pela prevalência da pandemia no país, entre as maiores do mundo, no momento da 
investigação. Com isso, prepara-se o caminho para melhor entendimento da vida futura pós pandemia.

\section{Self-fulfilling prophecy}

A SFP é uma lente teórica respeitável. Uma consulta ao Portal Periódicos da Capes comprova seu aproveitamento em artigos nas áreas de Psicologia, (1.569), Humanas (1.358), Educação (1.191), Sociologia (1.179), Negócios (875) e Economia (822).

Talvez a aplicação mais conhecida da SFP está na Educação, na sempre atualizada, discutida e contestada proposta do efeito Pigmaleão, de Rosenthal e Jacobson (1968) que, através de um experimento, postularam que as expectativas dos professores frente aos seus alunos têm efeito direto no desempenho deles. Haveria um ciclo aonde a concepção (no caso, falsa ou verdadeira) do professor A sobre o aluno B (por exemplo, que B é inteligente, interessado e merecedor dos melhores esforços), tem efeito nas ações de A sobre B (dedicando-lhe mais atenção), que molda a concepção de B sobre A; e, B age sobre A, em consonância com estas concepção (esforçando-se mais, tendo um desempenho superior), que reforça a concepção inicial do professor.

$\mathrm{Na}$ Sociologia, o conceito foi introduzido por Merton (1948), para quem uma definição, a princípio, errada (falsa) de uma dada situação, induz a adoção de um comportamento (diverso, se a definição fosse a correta) que por sua vez tem o resultado (não intencional e despercebido) de tornar verdadeira a concepção inicial. Assim, se $\mathbf{X}$ acredita que $\mathbf{y}$ é $\mathbf{p} ; \mathbf{X}$, portanto, faz $\mathbf{p}$; em função disso, $\mathbf{y}$ vira p (BRIGGS, 2011).

Exemplificando, durante a Depressão nos Estados Unidos, um rumor (incialmente falso) que dado banco não iria conseguir honrar seus compromissos, acarretou aumento inesperado nos saques e assim o banco viu-se insolvente, confirmando a expectativa, quando inicialmente e sem o rumor, poderia fazer face aos saques habituais (JUSSIM, 2020). Indicação semelhante, de validade da SFP, foi encontrada na relação entre o teor dos relatórios de auditoria e falências de empresas, ao se exacerbar as dificuldades financeiras preexistentes (GAEREMYNCK; WILLEKENS, 2003).

Fatores subjetivos são explicativos de casos de preços especulativos de ocorrências históricas - bolhas - como das tulipas holandesas (sec. XVII) e da empresa Mississippi, na França (sec. XVIII). A partir dessa constatação, Azariadis (1981, p. 396) aplicou a matemática a modelos estacionários para concluir que mesmo economias bem comportadas podem sofrer de flutuações, "se muitos indivíduos acreditarem ingenuamente que manchas solares ou algum dado índice de confiança são bons preditores de preços futuros, eles podem tomar decisões que tendem a sustentar suas crenças". Até a validade da lei de Moore, de duplicação periódica do número de transistores nos processadores, foi apontada como exemplo de SFP (FURBER, 2008). Afinal a projeção foi adotada como referência 
para as indústrias de semicondutores, que a suportaram com investimentos maciços em desenvolvimento e produção.

Diversos outros trabalhos testaram a SFP em negócios, economia e tomada de decisão, por exemplo: (i) reação do mercado aos comentários em uma coluna na revista Business Week (SANT; ZAMAN, 1996); (ii) efeito do SFP no mercado acionário chinês (WAN; YANG, 2019); e (iii) nos experimentos de Petalas, Shie e Vettehen (2017). Existe até mesmo uma interessante discussão de como teoria administrativa pode ser "performativa" - tornar-se válida pelo efeito da SFP (MARTI; GOND, 2018). Sendo assim, a SFP pode ser uma SFP; tomar uma especulação como SFP, teria o mérito convertê-la em SFP?

No caso desta pesquisa, hipoteticamente, se as construtoras acreditam que as pessoas vão continuar valorizando um hall, antessala, de descontaminação, passarão a oferecer essa disponibilidade. Os clientes podem perceber isso como padrão dominante e motivados pela expectativa de preservação de seu patrimônio em venda futura, passam a demandar o hall de descontaminação, que se valoriza, favorecendo aqueles que seguiram a expectativa em detrimento de outros, que não a observaram.

\section{Método de pesquisa}

A investigação assumiu a proposição ontológica subjetiva - a realidade como percebida, subordinando os processos de coleta, tratamento e análise de dados a tal ponto de partida. Resultouse em uma pesquisa descritiva, qualitativa, transversal e documental, que adotou os métodos descritos a seguir.

A fonte primária selecionada foi o jornal Folha de São Paulo, veículo de imprensa maior do país, e, assim, como maior potencial de ter matérias que, consumidas, podem vir a se tornar SFP, conformando o NN; em detrimento de (i) comunicação televistas e (ii) comunicação em blogs e mídias sociais; na expectativa - a se provar como razoável - que mensagens mais relevantes desses veículos, transbordem e acabem por serem incorporados na comunicação impressa convencional.

A busca se deu no site eletrônico do jornal nos primeiros dias de julho do ano corrente, com as expressões: "Novo Normal”, “pós pandemia”, “pós corona vírus”, "pós Covid 19”. Recuperou-se assim 1002 itens, que foram escrutinados através de análise prévia da temática, descartando-se as repetições. Posteriormente, o conjunto resultante foi submetido a seleção com base nos critérios: alinhamento (especulações sobre o NN), e diversidade (campos da vida em questão, autores e bases para a especulação).

Resultou-se em um corpus com 25 itens, numerados de C1 a C25 em função da data da publicação entre 02.05.2020 e 04.07.2020. Portanto, de 52 a 115 dias após reconhecimento da pandemia pela Organização Mundial da Saúde; quando, no país, os casos confirmados montavam 
91.589 e 1.539 .081 ; e as mortes totalizavam 6.329 e 63.174 , respectivamente - portanto na fase de crescimento acelerado da transmissão do coronavírus no Brasil. Nesse período, os municípios brasileiros começaram e avançaram a flexibilização, mesmo sem indicações da segurança do procedimento, enquanto outros países na Europa e na Ásia demonstravam, na prática, as mudanças com a flexibilização mais avançada, suportada pelo controle da pandemia. A Tabela 1 discrimina dados dos itens selecionados.

Tabela 1 - Itens para a composição do corpus

\begin{tabular}{|c|c|c|c|c|c|}
\hline$\overline{\mathbf{C}}$ & Data & Título & Autores & Construção & Assunto \\
\hline$\overline{\mathrm{C} 1}$ & $02 / 05 / 20$ & Máscaras e caixas de acrilico inundam salões de beleza na Austria & - & Entrevista & Negócio \\
\hline $\mathrm{C} 2$ & $08 / 05 / 20$ & Isolamento quebrou tabu de que churrasco não se embala para viagem & CUNHA, J; e outros & Entrevisa & Negócio \\
\hline $\mathrm{C} 3$ & $11 / 05 / 20$ & Escritórios na Faria Lima esvaziam, e empresas discutem o retorno & NARCISO, B & Entrevista & Trabalho \\
\hline $\mathrm{C} 4$ & $13 / 05 / 20$ & Mundo Pós-Covid 19: um mundo mais feminista & DINIZ, D & Ensaio & Comportamnto \\
\hline C5 & $16 / 05 / 20$ & Agenda para o Brasil no pós-pandemia & ANDRADE, RB & Ensaio & Economia \\
\hline C6 & $18 / 05 / 20$ & Consultoria lista 7 tendência para o mundo pós-coronavírus & PEZZOTI, R. & Consultoria & Economia \\
\hline $\mathrm{C} 7$ & $21 / 05 / 20$ & Cultura, ciências humanas e pandemia & MARTINS, F.; SILVA, MT & Ensaio & Ciências \\
\hline $\mathrm{C} 8$ & $23 / 05 / 20$ & Brasil, pare de burrice e valorize a bike... & SALLUM, E. & Outros jornais & Transporte \\
\hline C9 & $24 / 05 / 20$ & Como será a vida nas cidades após a pandemia & BERNARDES, C & Revista Foreign & Urbanismo \\
\hline $\mathrm{C} 10$ & $29 / 05 / 20$ & Hábitos de higiene e melhor interação com tecnologia são mantidos ... & MARRA, R. & Depoimentos & Comportamnto \\
\hline $\mathrm{C} 11$ & $04 / 06 / 20$ & Retomada da economia ... é oportunidade para descarbonizá-la & UNTERSTELL, N; PINHEIRO, GT & Ensaio & Economia \\
\hline $\mathrm{C} 12$ & $06 / 06 / 20$ & A quinta revolução industrial & PRATA, A & Ensaio & Trabalho \\
\hline $\mathrm{C} 13$ & $12 / 06 / 20$ & Novo normal: serviço self-service corre risco de ser extinto & TONON, R & Entrevista & Negócios \\
\hline $\mathrm{C} 14$ & $13 / 06 / 20$ & Mundo pós coronavírus terá menos gente nos escritórios & MELO, PC; SOPRANA, P. & Entrevista & Negócio \\
\hline $\mathrm{C} 15$ & $18 / 06 / 20$ & Cinemas, teatros e museus já se preparam para um novo normal ... & PASSOS, U. & Entrevista & Entretenimento \\
\hline $\mathrm{C} 16$ & $19 / 06 / 20$ & Limpeza será fator decisisivo para escolha de restaurante ... & PINHO, FG & Consultoria & Negócio \\
\hline $\mathrm{C} 17$ & $25 / 06 / 20$ & Após a pandemia: o risco de um tsunami autoritário & CLARIN & Ensaio & Política \\
\hline $\mathrm{C} 18$ & $26 / 06 / 20$ & Apocalipse causado por coronavírus pode tornar trabalho mais criativo ... & MASI, D. & Base bibliográfica & Economia \\
\hline $\mathrm{C} 19$ & $27 / 06 / 20$ & Airnb em crise com o coronavírus ... & BBC News & Entrevista & Turismo \\
\hline $\mathrm{C} 20$ & $27 / 06 / 20$ & O novo normal & PRATA, A & Crônica satírica & Comportamnto \\
\hline $\mathrm{C} 21$ & $29 / 06 / 20$ & Home office deve reduzir imóveis de escritórios mas não acabar com eles... & CUNHA, J; GRAZINI, M. & Entrevista & Construção civil \\
\hline $\mathrm{C} 22$ & $30 / 06 / 20$ & Sexo casual no novo normal & CARMEN & Ensaio & Comportamnto \\
\hline $\mathrm{C} 23$ & $01 / 07 / 20$ & Cuidar da vida: crise ecossocial e horizontes de futuro & - & Ensaio & Economia \\
\hline $\mathrm{C} 24$ & $04 / 07 / 20$ & Pesquisa na China mostra dez tendências de consumo pós-quarentena... & PERRIN, F & Consultoria & Comportamnto \\
\hline $\mathrm{C} 25$ & $04 / 07 / 20$ & Bolsas apontam oito setores preparados para o novo normal & MOURA, J. & Entrevista & Economia \\
\hline
\end{tabular}

Fonte: Elaborado pelos autores

A análise da Tabela 1 permite observar que as condições de diversidade de autores e de aspectos considerados foram cumpridas satisfatoriamente. Ademais, a entrevista foi o recurso mais utilizado na composição da peça, seguida de dados secundários (relatos de consultorias, outras fontes).

O corpus consequente (inteiro teor das peças selecionadas) e seus metadados (data da publicação, autores, localização, fonte de dados) foram transportados para um software de apoio a análise qualitativa.

Aplicou-se por fim a análise temática de conteúdo.

\section{Resultados e análise}

O dito e o não dito; ou mais preciso, o escrito e o não escrito, oferecem insights igualmente interessantes. 
Primeiramente, para a análise, haveria de se delimitar o espaço temporal da pandemia. O marco inicial poderia ser a data do reconhecimento pela Organização Mundial de Saúde (OMS) do estágio pandêmico associado ao coronavírus; opção com a conveniência de trabalhar com uma data universal e evidente. Mas haveria argumento razoável que esse marco seria mais fluído e particular, menos arbitrário, quando tal baliza fosse o momento em que o local começasse a "sentir" o impacto das medidas sanitárias, quer do governo local, quer irradiado de outras regiões. Em composição, o marco do final da pandemia é aberto: afinal, a OMS ainda terá de oferecer essa indicação (talvez em dois ou mais anos), mas é razoável imaginar que a pandemia, por qualquer critério, terminará em períodos diferentes por região ou país. As peças do corpus são omissas. Se isso é aceitável para o ponto inicial, é mais acintoso para o marco final, pois afinal os leitores precisariam ter pelo menos alguma indicação de quando seriam válidas as especulações, para confrontá-las. A questão oferece complexidade, pois dada as possibilidades de ondas sucessivas de contágios, o relaxamento inicial da quarentena não deve ser convencionado como final da pandemia, mesmo local.

Mais indeterminado ainda é o "Novo Normal". Parece que algumas obras no corpus o consideram no vai e vem da administração (intensificação - relaxamento) das medidas sanitárias. Outras, por ainda estar por vir, como no "pós-pandemia".

A imprecisão temporal é a regra. Se em um texto jornalístico isso é admissível, no esforço analítico é requerido alguma definição, mesmo que arbitrária. Então, para efeito dessa pesquisa, adotou-se como marco inicial da pandemia, a data da declaração de seu reconhecimento pela OMS, dia 11.03.2020 (alguns meses depois dos registros dos primeiros casos). Como marco inicial do NN, propõe-se, a partir da interpretação do corpus, quando começou o relaxamento mais generalizado das medidas sanitárias (liberação significativa das atividades do comércio e de serviços). Por simetria, o marco final da pandemia, seria quando a OMS o assim declarar. Portanto, haveria o período antes da pandemia (PAP), o período de início da pandemia até o final da primeira quarentena mais generalizada (PQG), o período novo normal (PNN), o período pós pandemia (PPP). Conforme pode ser observado na Figura 1, o período da pandemia comporta o PQG mais uma fração do PNN. O Brasil, a tempo das peças selecionadas, estaria já algum tempo, "construindo o novo normal" e obviamente, antes do final da Pandemia. Registra-se que é provável que alguns dos autores do corpus, especuladores do NN, não aceitem tal delimitação.

Figura 1 - Representação dos marcos analíticos.

$$
\begin{array}{r}
\hline-- \text { PAP ----- | (OMS) } \\
\mid \text {-----PQG ---- } \\
\text { (OMS) |----- PPP }
\end{array}
$$

Fonte: Elaborado pelos autores 
Vencida a questão do marco temporal, requer-se examinar outro aspecto relevante para teste da qualidade da especulação - se ela considerou cenários possíveis (e no caso até mesmo prováveis): como a descoberta da vacina e de tratamentos eficazes ou de recrudescimento da pandemia pelo surgimento de cepa mais contagiosa e letal. O resultado é interessante: apenas as matérias C13 e C14 trazem o ponto da vacina às suas especulações, ainda que de forma bem atenuada. Por exemplo, em C14, no depoimento de um dos entrevistados, da farmacêutica Johnson \& Johnson "a volta final (aos escritórios) dependerá de fatores externos. como melhora do quadro de saúde da população e alternativas de imunização, como vacina". Por outro lado, nenhuma das especulações do corpus trabalha com um cenário agravado.

Outro aspecto relevante é a presença/ausência de chamada para a precariedade da previsão. Quem sai melhor nesse quesito é C4, publicada em13/05/2020, sob o título: "Mundo Pós-Covid 19: um mundo mais feminista", que qualifica a sua especulação - o desamparo da sobrevivência pode fazer circular valores feministas (cuidado e interdependência) - como hipótese e alerta:

A verdade é que não sabemos; estamos como em um estágio intermediário de um rito de passagem - não mais como antes, mas ainda distantes do que surgirá depois dessas semanas de estranha suspensão do que conhecíamos como normalidade da vida. Não quero me portar como os homens sabidos que sobem aos palanques e fazem projeções .... como se o acaso pudesse ser controlado. A pandemia não estava prevista. Hipótese: (C4).

Outro destaque é C6: "algumas dessas mudanças são temporárias, enquanto outras terão um impacto duradouro, mas não sabemos o quanto. Mas sabemos que algumas coisas nunca serão as mesmas".

Com as exceções de C4 e C6, os trabalhos obtêm, na sua maioria, grau mínimo nesse indicador. Lendo-os, os desavisados podem tomá-los como garantidos.

Quanto a construção, existem aqueles que usaram o coronavírus apenas como âncora, pois as condições requeridas para as suas proposições já eram anteriores a pandemia, que assim veio apenas evidenciá-las, torná-las mais inevitáveis. Seria o caso da implantação de uma agenda socioambiental emancipadora (C10, C11, C17, C23). Ou de seu oposto, uma agenda liberal (C5). Até mesmo, a disseminação do uso urbano de bicicletas como política sanitária (C8) e a demonstração da eficácia do home office na pandemia para reorganização do trabalho e consequente revisão do modelo sociopolítico ao se garantir mais autonomia e criatividade para trabalhadores, mais produtividade para as empresas e um desenvolvimento mais igualitário (C18).

Outras matérias vislumbraram apenas o curto-prazo ao considerarem o NN como um alongamento, talvez atenuado ou adaptado, do comportamento e práticas adotadas no isolamento social, sempre não se prestando a quantificação e a definição de prazos, tais como:

- Uso de acrílico e máscara em salões de beleza (C1) 
- Fim do serviço de buffet, pelo menos tal como antes da pandemia com a adoção do grab and go, drive-thu, delivery, kits semiprontos, molhos e temperos com grife do estabelecimento e serviço simplificado. (C2, C13, C16)

- Consolidação do bome office (C3, C14, C21).

- Novas formas de crescimento (além do crescimento financeiro, como novos comportamentos); novo dinheiro (carteiras digitais e pagamentos biométricos); internet dos organismos e das coisas (monitorar a circulação); valorização do lar, do propósito, do consumo consciente, dos idosos; inteligência artificial; entretimento combinado com outros serviços, crescimento do senso de comunidade (C6)

- Extração de mais valor das tecnologias de informação e comunicação (por exemplo, para estudar), valorização das coisas simples (canto de passarinho). Práticas de higiene e sanitárias (tirar sapato antes de entrar em casa, lavar compras, uso de máscara, lavar as mãos, meditação, relaxamento). Investimento em empresa e projetos que apoiam o desenvolvimento social. Percepção das futilidades (C10). Em C10 é declarado: "muita gente descobriu que os novos hábitos trazem benefícios no dia a dia e ajudam com uma melhor qualidade de vida. Por isso, pretendem manter as práticas mesmo depois da quarentena".

- Em teatro, cinemas e museus: plateias esvaziadas, exposições com percurso único e espetáculos mais curtos. Protocolos com base nas experiências internacionais, instruções da OMC, autorregularão, e decretos de autoridades públicas. Preferência por apresentação ao ar livre, fim dos ingressos e dos guarda-volumes, interações restritas entre clientes. Agendamento de visitas a museu.

- Redistribuição dos lugares para onde se viaja (turismo interno)

- Lives: empresas fazendo transmissão ao vivo em parceria com influenciadores. Entrega imediata de delivery. Pagamentos remotos. Telemedicina. Alimentação saudável e exercícios. Fuga do transporte público. Valorização de fontes confiáveis. Compras locais e compras online. Permanência em plataformas virtuais. (C24, ainda estabelece: "antes da pandemia produtos de limpeza falavam em eficiência, rendimento. Agora o foco é o cuidado com a saúde”).

- Pelos púbicos. Sexo virtual. Aumento de vendas de apetrechos sexuais (telediltos, vibradores controlados por aplicativo à distância). Relações poli afetivas abertas (C22).

É razoável admitir que previsões de curto prazo tais como as citadas, de mera extensão adaptada de um período anterior, de baixo risco e imprecisas, têm maior chance de obter o status de SFP, mas isso não as torna necessariamente mais interessantes. 


\section{Conclusão}

O mundo parece lidar com as incertezas fazendo apostas, especulando, sobre o futuro em um presente cinzento e turbulento. São numerosas as previsões para o Novo Normal (até mesmo de que ele seja ficção; que haveria um retorno triunfal do "Velho Normal" quando vacinas e tratamentos eficazes estiverem disponíveis).

Algumas especulações podem se concretizar ou assim o parecer, nesse caso, em função de sua imprecisão técnica (falta de prazo e de quantificação). A literatura é rica em afirmar que crença em previsões pode mudar o futuro, tornando-a uma SFP. Não é possível apontar quais das 25 matérias têm potencial de SFP. Talvez isso não seja reconhecido nem a posteriori, pois é difícil isolar o efeito de autorrealização. O fato de tais previsões serem passíveis de reprovação técnica como as apontadas nesse estudo, não reduz seu potencial de SFP, somente associado ao grau com que as pessoas acreditam nelas e alteram seu comportamento em decorrência dessa crença.

\section{Referências}

AZARIADIS, C. Self-fulfilling prophecies. Journal of Economic Theory, v. 25, p. 380-396, 1981.

BERGER, P. L.; LUCKMANN, T. The social construction of reality: a treatise in the sociology of knowledge. New York: Randon House, 1966.

BRIGGS, M. Cap.13 Self-fulfilling prophecy. In: HEDSTRÖM. P; BEARMAN, P. S. (ed.). The Oxford handbook of analytical sociology. New York: Oxford University Press, 2011.

FURBER, S. The future of computer technology and its implications for the computer industry. The Computer Journal, v.51, n. 6, p.735-740, 2008.

GAEREMYNCK, A.; WILLEKENS, M. The endogenous relationship between audit-report type and business termination: evidence on private firms in a non-litigious environment. Accounting and Business Research, v. 33, n.1, p.65-79, 2003.

JUSSIM, L. Self-fulfilling prophecy. In: Encyclopædia Britannica, 2020. Disponível em www. britannica.com / contributor/Lee-Jussim/9782908, acesso em 06.07.2020.

MARTI, E.; GOND, J-P. When do theories become self-fulfilling? Exploring the boundary conditions of performativity. Academy of Management Review, v. 43, n.3, 19p. 2018.

MERTON, R. K. The self-fulfilling prophecy. The Antioch Review, v. 8, n. 2 (Summer), p. 193$210,1948$.

PETALAS, D. P.; SHIE, H.; VETTEHEN, P. H. Forecasted economic change and the self-fulfilling prophecy in economic decision-making. PLoS ONE, v. 12, n. 3, 13p., 2017. 
ROSENTHAL, R.; JACOBSON, L. Pygmalion in the classroom. New York: Holt, Rinehart and Winston, 1968.

SANT, R. ZAMAN, M. A. Market reaction to Business Week 'Inside Wall Street' column: a selffulfilling prophecy. Journal of Banking \& Finance, v. 20, s/n., p. 617-643, 1996.

WAN, Y.; YANG, X An empirical study of the self-fulfilling prophecy effect in Chinese stock market. The Journal of Finance and Data Science, v.5, s/n, p. 116-125, 2019. 